\title{
How to Cultivate Students' Core Literacy in the Unit Introduction Course? Take Middle School English as an Example
}

\author{
Yunjie $\mathrm{Xu}$ \\ Xingcheng School, Suzhou Industrial Park, Suzhou, China
}

\begin{abstract}
Cultivating students' core literacy is an important mission of contemporary education. Teachers should fully understand the core literacy and infiltrate the core literacy of English subjects into daily classroom teaching. Comic Strip \& Welcome to the Unit is a unit introduction course, which plays a key role in the teaching of English texts. However, in daily teaching, there are problems of patterning and surface layering. We will discuss how to cultivate students' core literacy in the middle school English unit introduction course. Based on the analysis of excellent class cases, we will propose corresponding teaching strategies.
\end{abstract}

Sci Insigt Edu Front 2019; 3(2):323-330.

Doi: 10.15354/sief.19.ar102

Keywords: Core Literacy; Unit Introduction Course; Teaching Strategy;

Middle School English

Correspondence to: Yunjie Xu, Xingcheng School, Suzhou Industrial Park, Suzhou, Jiangsu, China. Email: 466973780@qq.com

Conflict of Interests: None. 
$\mathrm{T}$

HE Ministry of Education of China put forward the concept of "core literacy" in the "Opinions on Comprehensively Deepening Curriculum Reform and Implementing the Fundamental Tasks of Establishing Morality and Educating People" in 2014. In September 2016, the "China Student Development Core Literacy" was promulgated, in which a systematic and authoritative discussion on what kind of people should be cultivated and how to train people was made. In English teaching, teachers should combine the instrumentality and humanity of English subjects to cultivate students' core literacy of English subjects (Cheng \& Zhao, 2016), and lay a solid foundation for students' lifelong development.

Introduction is a way for teachers to guide students into learning behavior quickly before starting new teaching contents (Feng \& Ge, 2008). A good unit introduction course can guide students to understand the central topic of the unit and stimulate students' interest, thus laying the foundation for the whole unit learning. Comic Strip \& Welcome to the Unit as a unit introduction class, mainly through the interesting dialogue between Hobo and Eddie in the Comic Strip section, and then through the simple exercises in the Welcome to the Unit section and the characters in the book to let students learn about the central topic and core grammar knowledge of this module.

However, in daily teaching, the introduction process has not been well valued, and it is often perfunctory with a few minutes of "reading" and "speaking". Such views and teaching methods cannot invoke students to be interested in the topic, and cannot effectively introduce the whole unit, and cannot reach the purpose of cultivating students' core literacy.

\section{The Basic Content of the Core Literacy of English Subjects}

In combination with the practical needs of the English course for basic education in China, the core literacy of English can be summarized into four aspects: language ability, cultural character, thinking quality and learning ability (Cheng \& Zhao, 2016). Language ability mainly refers to the ability to understand and express by language in social context (Cheng \& Zhao, 2016). In addition to basic listening, speaking, reading and writing skills, it also includes the ability to communicate with others. Cultural character refers to the understanding of Chinese and foreign cultures and the recognition of excellent culture. It is the cultural awareness, humanistic cultivation and behavioral orientation of students in the context of globalization (Zhang, 2019). The quality of thinking is an indicator that distinguishes one's thinking and evens the level of intelligence and level, including profundity, flexibility, creativity, criticality and agility (Chen, 2019). Learning ability refers to students actively using and actively adapting English learning strategies, broadening English learning channels, and improving the awareness and ability of English learning efficiency. 


\section{Frequently Asked Questions in the Middle School English Unit Introduction Course}

At this stage, the research on core literacy majorly focuses on reading teaching, because English reading plays a key role in improving students' core literacy, especially language ability, cultural character, thinking quality and learning ability (Wang, 2017). The content of the conversation in the unit introduction also belongs to the reading, so the introduction course plays an essential role in cultivating the core literacy. However, in the daily teaching of middle school English, the unit introduction has the following common problems:

(1) Classroom teaching is too modeled. The Comic Strip section only allows students to take a look and play. The Welcome to the Unit section only allows students to complete questions and imitate conversations.

(2) The teacher did not have an in-depth interpretation of the teaching materials. The classroom questions lacked the thinking depth and the questions were too simple.

(3) The classroom pays too much attention to the explanation of words and grammar, but ignores the cultivation of students' cultural character and learning ability.

The above problems reflect that the focus of middle school English is mostly on language learning, but not on the development of students' literacy (Lu, 2015).

\section{Teaching Strategy and Operation Cases of Middle School English Unit Introduction Course}

\section{Set Up an English Learning Situation}

Language comes from life, and language is used in real life situations. In order to make students feel the sense of reality, reality and demand for learning and using English, teachers should create situations that are close to their life experience (Wang, 2016).

The Compulsory Education English Curriculum Standard (2011 Edition) advocates language learning and usage in corresponding context. In the teaching of the unit introduction, the whole class should have a main line to create a learning situation, and then design a series of tasks around the situation, so as to achieve the final teaching goal, that is, "a main line, a series of tasks, and a goal."

\section{Case 1}

Taking the teaching of $7 B$ Unit 8 Pets as an example, the introduction course of this unit is mainly about different kinds of pets and let students talk about their favorite pets and reasons.

According to the content of the textbook, the teacher created the situation of participating in the pet club, and designed the three links as know about pets, why we like pets, and be a good master. In the part of know about pets, teach different types of 
pets, such as goldfish, mouse, and parrot, etc. In the second part, why do we like pets? Based on the dialogue in the book, organize students to discuss their favorite pets and reasons. In the last part, according to the story of Hobo and Eddie, the question of Is Eddie a good master? is given to guide students to think about how to be a good master, to stimulate the emotional experience of the students, and to change students' thinking and promote individual students.

In the process of teaching, teachers purposely create specific situations, let students learn new words, practice dialogues in real situations, and stimulate students' emotional experience.

\section{The Blending of Chinese and Foreign Cultures}

The ultimate goal of cultural character in core literacy is to cultivate people with a global vision and a feeling of home nation, culture and social responsibility (Gao, 2017). Cultural knowledge is the basis for shaping cultural character. In teaching, teachers can integrate Chinese and foreign cultures, such as Chinese and Western cultural differences, British and American traditional culture and so on.

\section{Case 2}

Take $7 A$ Unit 5 Let's Celebrate as an example. The introduction course of this unit is mainly to introduce traditional festivals at home and abroad.

The teacher first introduces traditional Chinese holiday customs through pictures, such as the watch fireworks, get red packets, eat dumplings, and visit relatives and so on. In addition, the wonderful Western festivals should also be integrated into the classroom, such as the traditional activities of Halloween pumpkin lanterns, dress up as a ghost, play trick or treat, and Thanksgiving family reunion to eat turkey. Through the blending of these Chinese and foreign cultures, it not only stimulates students' interest, but also makes students recognize the cultural differences between different countries and enables students to have an international perspective.

The textbook contains a lot of Chinese and foreign cultural knowledge, such as $7 B$ Unit 1 introduces famous countries and their capitals; 8B Unit 4 explains famous Chinese and foreign books. We should start with the textbooks, find cultural information, infiltrate into the teaching, and broaden the horizons of students. In addition, the development of cultural experience between Chinese and foreign schools can also promote the formation of cultural character.

\section{Broaden Thinking Space}

The quality of thinking in the four aspects of English core literacy is relatively stable. The thinking quality is not formed within a day, but it requires gradual guidance and penetration through daily teaching. More ideal middle school English classes should allow students to think constantly than that as a seemingly lively class. The questions in 
the classroom should not only the closed questions like "Yes" or "No" answers, but should overcome the students' thinking obstacles and broaden their thinking space.

\section{Case 3}

Take $8 B$ Unit 8 A Green World as an example. This unit is about green living. The teacher creates a situation with questions like: What is a green life? How to live a green life? Why do we live a green life? In the section of "How to live a green life?", Hobo said "Trees are good for us." In the process of teaching, the teacher continued to ask "Why are trees good for us?", which let the student think in different ways. From the perspective of thinking, there is no fixed answer, students can speak freely and broaden the spectrum of thinking, and the teachers are also very pleased to get the students' wonderful answers: keep the air clean, reduce dust, and keep soil in place and so on. After understanding a lot of green lifestyles, then the students start to think about the meaning of green life. This training students' thinking quality helps students develop their thinking ability.

At the end of this lesson, the instructor inspires students to review the connotation of green life according to Figure 1, so that students can resonate emotionally, and then let students begin to think about what is green life, and correspond to each other. The students also said "A green life is a balance between development and environment, a balance between cities and forests and other answers".

To cultivate students' thinking quality, first of all, teachers should have a thorough understanding of the text. Secondly, they should cultivate students' selfconfidence in the classroom; discover the bright points in the students' thinking, and give encouragement in time, not because they are different from their own presets. Students are interrupted and students are encouraged to express themselves in the English class.

\section{Advocate Self-Directed Learning}

English learning ability includes not only learning methods and strategies, but also understanding and attitudes. In addition to the traditional instillation teaching mode, we need to adopt rich and innovative teaching methods to achieve better teaching results in the daily teaching.

\section{Case 4}

Taking $7 B$ Unit 8 Pets as an example, in the final stage, four students form a group (each responsible for leader, recorder, reporter, time-keeper) to complete the task of Part A Pet's Self-Statement in Figure 2. Through the group learning model, the time is returned to the students, the student's classroom subject status is strengthened, the students are exchanged and discussed in the group, and their English thinking is activated. Through the form of peer learning and promotion, the enthusiasm and efficiency of learning has been significantly improved. In addition to the group learning mode, "Mr. 


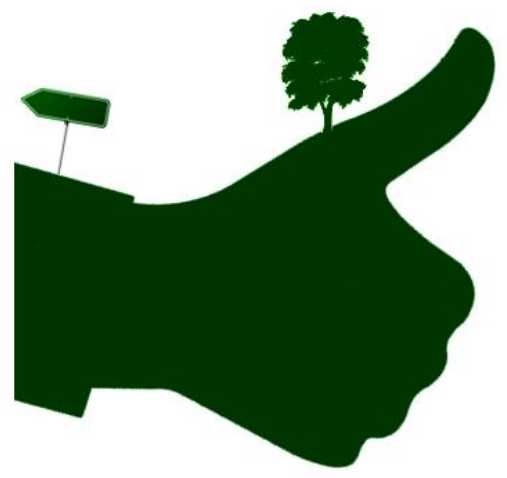

A Green Life

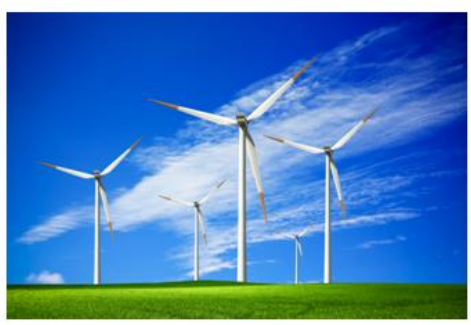

Green Energy

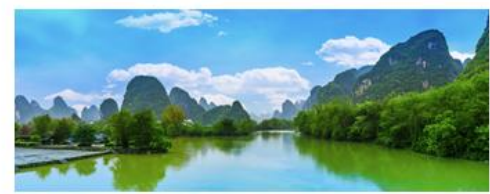

\section{Natural Resources}

\section{A Green World is A Balance between} and

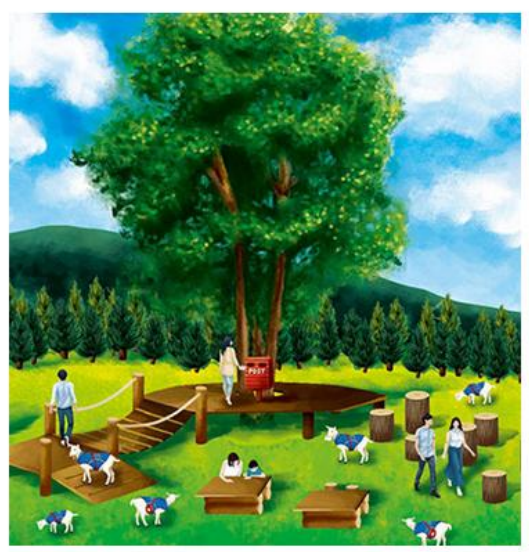

Master Mode" is also a method that can be tried. If the teaching content is relatively simple, students can come to the lecture. Students are more willing to learn from each other than to listen to the teacher. In this way, the students in the lectures are carefully prepared for the lesson, and the knowledge is digested in the course of preparing lessons. The cultivation of students' core literacy is not something that can be done independently in a certain class or at a certain stage. This requires teachers to always cultivate the core literacy of students in the teaching, and to regard the "all-round development" as the core of training. In order to realize the effective implementation of the unit introduction course, it is necessary to use the core literacy as a guide to determine clear teaching 


\section{A Pet's Self-statement}

Hello, everyone. I'm a My master keeps me as a pet because I am I feel happy most of the time. But sometimes Ifeel really hurt because he/ she . So, I advise that my master can I love my master very much and I hope we can live a happy life together.

objectives, create a situation close to real life, and design a task that can broaden students' thinking and integrate certain Chinese and foreign cultures. Advocate students to learn independently, give full play to their initiative and imagination, enable students to actively integrate and fully enjoy the whole class, and truly realize the cultivation of students' core literacy of English subjects.

\section{References}

Chen, Z., Wang, W. \& Qian, X. (2019) On the thinking quality and its development ways in the core literacy of English subjects. Teach Mat Teach Meth, (1):91-98.

Cheng, X. \& Zhao, S. (2016) The substantial connotation of core competence of Eng- lish discipline. Teach Mat Teach Meth, (5):79-86.

Feng, Y. \& Ge, Y. (2008) A new probe into the introduction art of efficient English teaching classroom. Heilongjiang Sci Tech Info, (6):146. 
Gao, H. (2017) Cultural character objective: an important development of English courses. Eng Learn, (1): 6-9.

Lu, Z. (2015) The possibility of English teaching to promote the development of thinking quality. Eng Learn, (12): 20-24

Ministry of Education of China. (2014) Opinions on comprehensively deepening curriculum reform and implementing the fundamental tasks of establishing morality and educating people. http://www.moe. edu.cn/publicfiles/business/htmlfiles/moe/ s7054/201404/167226.html.

Ministry of Education of the People's Republic of China. (2012) Compulsory educa- tion English curriculum standards (2011 Edition). Beijing: Beijing Normal University Press.

Wang, W. (2017) English reading teaching under the background of core literacy: problems, principles, goals and paths. Eng Learn, (2): 19-23.

Wang, W. (2016) Three key words to promote the transformation of English teaching methods: "situation", "questions" and "activity”. Basic Edu Curric, (3): 45-50.

Zhang, W. (2019) Cultural character cultivation under the core of English teaching. Art Sci, (7):34-35.

Received: 06 July 2019

Revised: 18 July 2019

Accepted: 15 August 2019 